\title{
Abnormalities of oesophageal mechanoreceptors in canine acrylamide neuropathy
}

\author{
PM SATCHELL, JG MCLEOD \\ From the Department of Medicine, University of Sydney, Australia
}

SUMMARY Dogs exposed to acrylamide develop peripheral neuropathy and megaoesophagus. The properties of slowly adapting oesophageal mechanoreceptors were studied in six control and five acrylamide affected greyhounds in which the oesophagus had been surgically isolated under anaesthesia and oesophageal pressure was controlled while monitoring impulses in oesophageal afferent fibres in the cervical vagus. In the acrylamide affected animals oesophageal afferent units had elevated thresholds and significantly reduced firing rates during ramp increases in oesophageal pressure. It is concluded that abnormalities of oesophageal mechanoreceptors may be important in the pathogenesis of certain oesophageal motility disorders in man and animals.

Chronic exposure to acrylamide causes a distal axonopathy manifested as a sensorimotor neuropathy in man and many animal species. ${ }^{12}$ Acrylamide neuropathy has been used as a model of the dying back neuropathies in man. The condition in the dog is similar clinically, morphologically and electrophysiologically to that of other species, except that a prominent feature is the development of megaoesophagus which has been considered to be the result of damage to vagal afferent fibres. ${ }^{34}$ Since it is well established that the earliest detectable morphological and functional changes in acrylamide neuropathy are in sensory receptors, ${ }^{15-7}$ the present study was undertaken in order to compare the properties of slowly adapting oesophageal mechanoreceptors innervated by vagal afferents in control dogs with those in animals with acrylamide neuropathy. The normal function of oesophageal mechanoreceptors in the dog has been previously reported. ${ }^{8}$ Vagal dysfunction and oesophageal motility disorders are present in alcoholic and diabetic neuropathy in man and the findings in the dog may assist in the understanding of the mechanism of gastrointestinal dysfunction in these conditions.

\section{Methods}

\section{Animal preparation}

Eleven greyhounds were studied. The details of animal

Address for reprint requests: Dr PM Satchell, Sobell Department of Neurophysiology, Institute of Neurology, Queen Square, London WCIN 3BG, UK.

Received 8 December 1983

Accepted 30 January 1984 care, the clinical signs of neuropathy and the features of the feeding disorder have been described elsewhere. ${ }^{3}$ Five animals received acrylamide twice weekly in a capsule at a dose of 5.5-6.0 $\mathrm{mg} \mathrm{kg}^{-1}$ day $^{-1}$. Radiological studies of the oesophagus were carried out on all acrylamide affected animals on two occasions, the second examination always being conducted within four days of the terminal experiment. Animals were anaesthetised with sodium pentobarbitone (30 mg/kg); deep surgical anaesthesia was maintained by additional doses as required. Animals were intubated and ventilated with a Bird Mk 8 respirator using a $50 \%$ oxygen-air mixture; efficiency of ventilation was checked by blood gas estimations (ABL2 Blood Gas Laboratory). Systemic blood pressure was measured from a cannula in the right brachial artery (Sanborn 267B Pressure Transducer) and rectal temperature was monitored (Grant Thermistor Thermometer). Both blood pressure and temperature remained at physiological levels throughout. Tracheal air flow was measured with a pneumotachograph (Mercury Electronics).

\section{Oesophagus isolation}

The cranial end of the oesophagus was approached through a midline neck incision. Taking care to protect left and right vagi, spaces were formed anterior and posterior to the oesophagus, and binding tape passed around the oesophagus, but not tied. A left thoracotomy between the eighth and ninth ribs allowed binding tape to be passed around the supradiaphragmatic oesophagus excluding the dorsal and ventral vagal trunks. The lower oesophagus was tied off $2-3 \mathrm{~cm}$ above the diaphragmatic insertion. An oesophageal access tube (inner diameter $11 \mathrm{~mm}$ ) was passed into the upper oesophagus through the mouth and the binding tape tied securely around it. The access tube was connected to a perfusion bottle filled with warmed Hartman's solution. The bottle was pressurised with oxygen and any pressure level between 0 and $60 \mathrm{~mm} \mathrm{Hg}$ could be 
maintained, and ramp pressure changes produced. Oesophageal pressure was measured with a catheter, the tip of which lay in the distal opening of the access tube (Sanborn 267B Pressure Transducer). The reference point for zero pressure was the midline of the cervical oesophagus with the dog in the right lateral position.

\section{Vagus nerve preparation and recording}

A set of stimulating electrodes used to produce oesophageal contraction was placed on the right vagus 3-4 $\mathrm{cm}$ cranial to the upper sternal margin. Stimulating electrodes used to measure conduction velocity were placed on the left vagus at the same level. Each set of electrodes was connected to a stimular (Digitimer Isolated Stimulator: Model DS2), which delivered 0.1 ms square wave pulses at a rate determined by a programmable stimulator (Frederick Haer Co.: Pulsar 6i). Single fibre and few fibre nerve strands of the left vagal trunk at the level of the carotid bifurcation were prepared by teasing under warmed oxygenated mineral oil on a black perspex platform using a dissecting microscope and jewellers' forceps. Nerve activity was recorded with silver-silver chloride electrodes, amplified and stored on magnetic tape, as were oesophageal pressure and airflow (Electrodata 6400 FM Tape Recorder). All pressure ramps were performed with the respirator stopped to avoid modulation of oesophageal pressure by the lungs.

Mixed nerve conduction velocity was determined by stimulating supramaximally the left vagus at the base of neck and recording the mixed nerve action potential of the whole nerve at the level of the carotid bifurcation. The response to 30 stimulating shocks was averaged by the PDP 11/40 computer and the latency was measured from the stimulus artefact to the onset of the first negative deflection. Conduction distance between the electrodes was measured with calipers.

The conduction velocity of the cervical portion of single afferent fibres innervating oesophageal mechanoreceptors was determined using collision techniques. ${ }^{910}$ The receptor site was located by digital manipulation of the intrathoracic oesophagus.

Firing rate was determined by replaying the recording into a digital window (PDP 11/40 Computer). Firing rate, oesophageal pressure and airflow were displayed on a polygraph (Grass Model 7). Mean firing rate was obtained by filtering (half amplitude frequency of $3 \mathrm{~Hz}$ ).
Statistics

A non-parametric statistical method (Mann-Whitney test) was used to compare results in the two groups of animals; a value of $p<0.05$ was regarded as significant.

\section{Results}

CLINICAL FEATURES (table 1)

The clinical signs of neuropathy in the dog exposed to acrylamide consist of toe scuffing, ataxia, muscle weakness and toe folding. ${ }^{3}$ All four signs were observed in three of the animals, while toe folding was absent in the remaining two. All five affected dogs had radiological features of early oesophageal malfunction, such as prolonged retention of contrast, mild dilatation and enlarged bolus size. However, regurgitation of food and radiological evidence of overt megaoesophagus developed in only two of the animals (A30 and A39).

\section{VAGAL AFFERENT FIBRE DISCHARGE WITH UNDISTENDED OESOPHAGUS}

On monitoring the massed nerve activity of the entire desheathed vagus, the electrical silence in the nerves of acrylamide affected animals was in striking contrast to the activity of the vagi of controls, in which prominent respiratory and cardiac rhythms were obvious.

Recordings were made from eighteen vagal afferent fibres in control animals and from nineteen fibres in acrylamide affected animals. The threshold of each oesophageal mechanoreceptor unit was defined as the oesophageal pressure at which a spike discharge began during a pressure ramp. In the pressure range of $0-1 \mathrm{~mm} \mathrm{Hg}$ all control units discharged with irregular firing rates (mean, $2.9 \mathrm{~Hz}$; range, $0 \cdot 2-13 \cdot 0 \mathrm{~Hz}$ ), but there was no spontaneous activity in any of the affected animals (figs 1 and 2). However, in both groups of animals, all units responded to an increase in oesophageal pressure with a sustained increase in discharge rate.

Table 1 Clinical features of dogs exposed to acrylamide

\begin{tabular}{|c|c|c|c|c|c|c|c|c|}
\hline \multirow{2}{*}{$\begin{array}{l}\text { Animal } \\
\text { number }\end{array}$} & \multirow{2}{*}{$\begin{array}{l}\text { Toe } \\
\text { scuffing }\end{array}$} & \multirow{2}{*}{$\begin{array}{l}\text { Muscle } \\
\text { weakness }\end{array}$} & \multirow{2}{*}{ Ataxia } & \multirow{2}{*}{$\begin{array}{l}\text { Toe } \\
\text { folding }\end{array}$} & \multirow[t]{2}{*}{ Regurgitation } & \multirow{2}{*}{$\begin{array}{l}\text { Radiological appearance } \\
\text { of oesophagus }\end{array}$} & \multicolumn{2}{|c|}{ Dose of acrylamide } \\
\hline & & & & & & & $m g K^{-1}$ & $m g \boldsymbol{k g}^{-1} \mathrm{day}^{-1}$ \\
\hline A30 & + & + & + & - & + & Megaoesophagus & 370 & $5 \cdot 7$ \\
\hline A31 & + & + & + & + & - & $\begin{array}{l}\text { Mild dilatation with persistence } \\
\text { of contrast } 15 \mathrm{~min} \text { after } \\
\text { swallowing }\end{array}$ & 310 & $5 \cdot 5$ \\
\hline A32 & + & + & + & - & - & $\begin{array}{l}\text { Enlarged bolus size. No } \\
\text { oesophageal dilatation or } \\
\text { persistence of bolus }\end{array}$ & 320 & $5 \cdot 6$ \\
\hline A33 & + & + & + & + & - & Mild dilatation & 330 & $5 \cdot 8$ \\
\hline A39 & + & + & + & + & + & Megaoesophagus & 330 & $5 \cdot 9$ \\
\hline
\end{tabular}

$+=$ present

$-=$ absent 
$\stackrel{\text { o }}{1}_{\text {ह }}^{a}{ }_{0}^{a}$

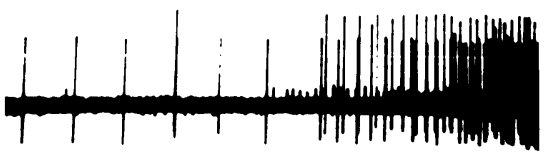

b

$\stackrel{\text { ô }}{\text { ह }}_{\text {हn }}^{5}[$

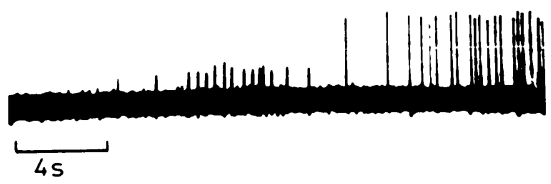

Fig 1 Neural activity recorded from vagal afferent fibres in response to oesophageal pressure. Upper trace, oesophageal pressure; lower trace, vagal afferent nerve activity. In a control animal (a) 3 oesophageal units are firing tonically in the pressure range of $0-1 \mathrm{~mm} \mathrm{Hg}$; the rate of discharge increases with the rise in pressure. In an acrylamide affected animal (b), there are no units firing tonically in the pressure range $0-1 \mathrm{~mm} \mathrm{Hg}$ but discharges commence as the pressure rises.

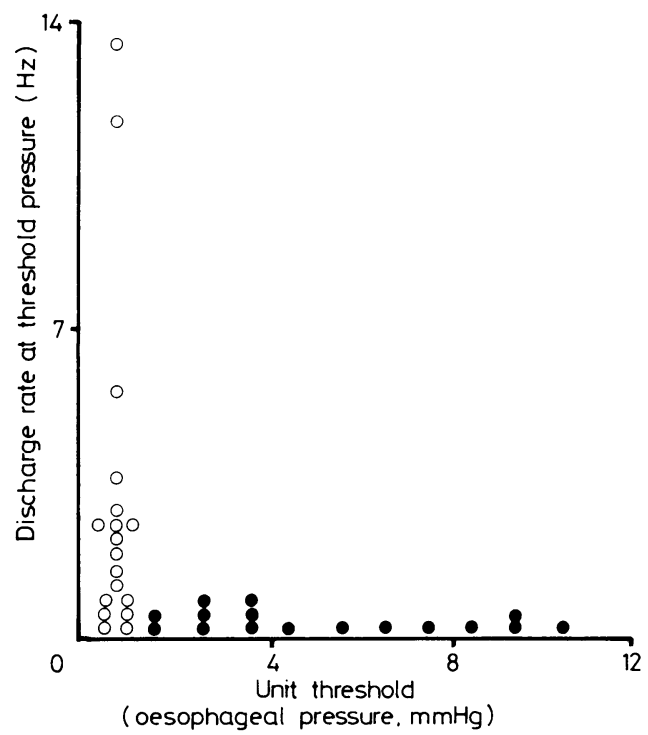

Fig 2 Threshold of units responding to oesophageal pressure. Eighteen control units (open circles) were discharging tonically in the pressure range $0-1 \mathrm{~mm} \mathrm{Hg}$. Sixteen units from acrylamide affected animals (filled circles) were silent at $0-1 \mathrm{~mm} \mathrm{Hg}$ but began to discharge during pressure ramps at threshold pressures ranging from 1-10 $\mathrm{mm} \mathrm{Hg}$.

\section{OESOPHAGEAL AFFERENT FIBRE DISCHARGE}

DURING PRESSURE RAMPS AND OESOPHAGEAL CONTRACTIONS

Oesophageal pressure ramps provoked a sustained increase in oesophageal mechanoreceptor discharge in both groups of animals. However, discharge rates were markedly reduced in affected animals (figs 3, 4). During pressure ramps of similar gradients, the mean firing rates of units in control animals were significantly different from units in acrylamide affected animals at all levels of pressure sampled ( $p$ $<0 \cdot 01)$. When the firing rates of units with similar conduction velocities were compared (conduction velocity $<18.4 \mathrm{~m} / \mathrm{s}$ ), the discharge rate in the units from affected animals was significantly lower $(\mathrm{p}<$ $0 \cdot 01$ ) than those in control animals with comparable conduction velocities (fig 4b).

Whereas most units from control animals exhibited a regular, progressive increase in discharge
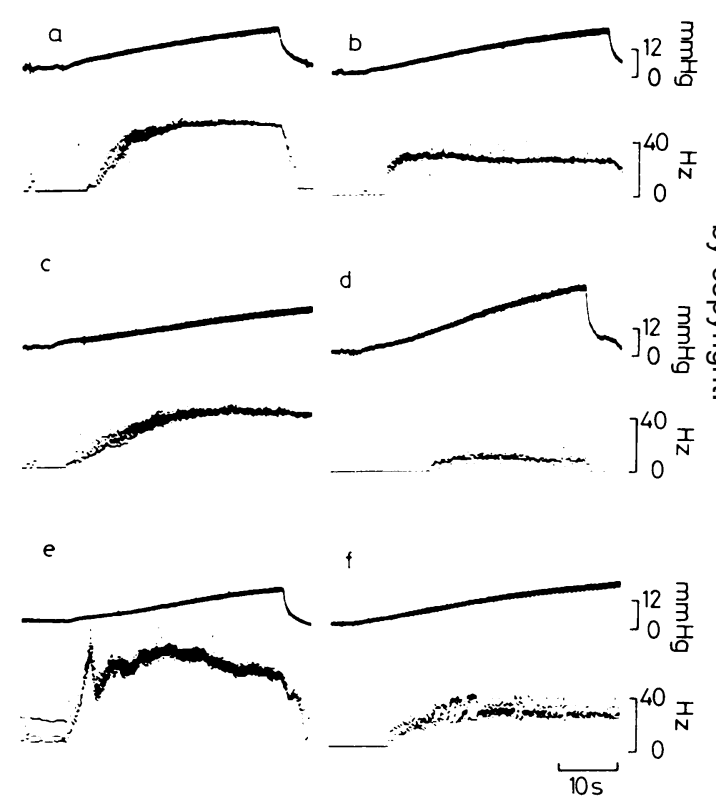

Fig 3 The discharge characteristics of oesophageal mechanoreceptors in three control $(a, c, e)$ and three acrylamide affected $(b, d, f)$ units during pressure ramps. Upper trace, oesophageal pressure; lower trace, impulse frequency. $a$ and $c$ illustrate typical responses in normal units. $b$ depicts the most briskly responding of the units from acrylamide affected animals; firing started suddenly at $a$ pressure of $3 \mathrm{~mm} \mathrm{Hg}$, and impulse frequency is markedly reduced compared to control units. The threshold of $d, a$ more typical acrylamide unit, is even higher and the firing rate lower than those of the unit shown in b. $c$ depicts a burst response in a control unit as pressure increased. The firing rate of the unit in $F$, from an affected animal, was extremely irregular oscillating between 24 and $36 \mathrm{~Hz}$. 


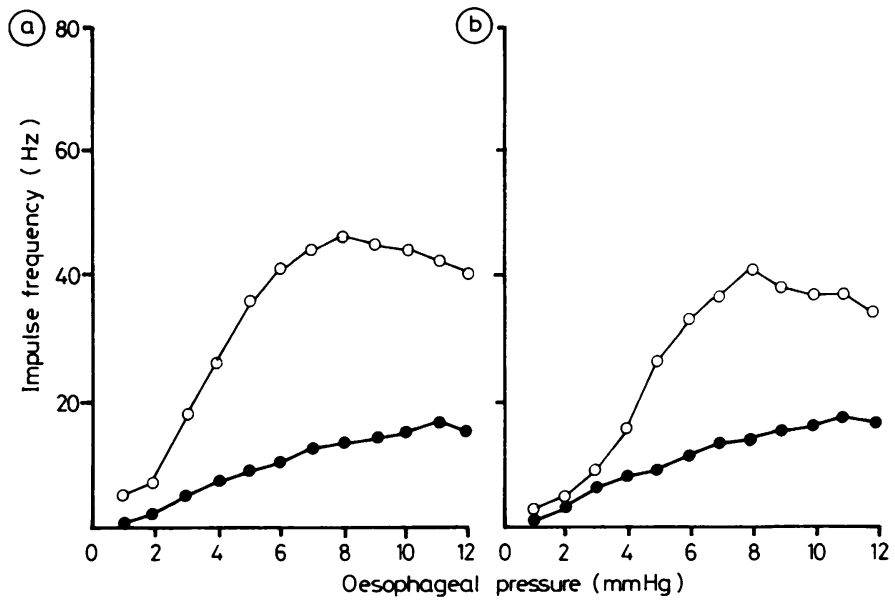

Fig 4 a. The relationship between impulse frequency and oesophageal pressure in control and acrylamide affected animals during pressure ramps of similar gradient. Open circles, mean of 14 control units; closed circles, mean of 11 units from acrylamide affected animals. The frequency of discharges were significantly different at all levels of pressure $(p<0.01)$. b. Relationship between impulse frequency and oesophageal pressure in units of conduction velocity less than 18.4 $\mathrm{m} / \mathrm{s}$ from control (open circles) and acrylamide affected animals (closed circles). The impulse frequencies were significantly different $(p<0.01)$ except at oesophageal pressures less than $4 \mathrm{~mm} \mathrm{Hg}$. rate as oesophageal pressure increased (fig $3 a, c$ and e), many units from affected animals were silent during the initial part of the ramp, and then abruptly commenced firing (fig 3b). "Burst" responses, which are characteristic of normal oesophageal mechanoreceptors, ${ }^{8}$ were observed in three of the units from control animals (fig $3 \mathrm{e}$ ), but not in affected animals; units from affected animals did, however, occasionally discharge irregularly (fig 3f).

In both groups of animals, stimulation of the right vagus at $20 \mathrm{~Hz}$ for 5 seconds produced a contraction of the oesophagus, accompanied by marked bradycardia. The mean peak oesophageal pressure produced with the oesophageal access tube closed was $11 \mathrm{~mm} \mathrm{Hg}$ (range $9-17 \mathrm{~mm} \mathrm{Hg}$ ) in five control animals and $8 \mathrm{~mm} \mathrm{Hg}$ (range, $4-13 \mathrm{~mm} \mathrm{Hg}$ ) in four acrylamide affected animals. The pattern of oesophageal afferent discharge in response to isometric (oesophageal access tube closed) and isotonic (access tube open) contraction was similar in both groups of animals, but the discharge rates in affected animals were generally lower (fig 5).

The distribution of receptors along the thoracic oesophagus located by digital manipulation was indistinguishable in control and affected animals. When locating the receptors, it was noted that in control animals the slightest distortion of the empty oesophagus in the region of the receptor under study provoked a marked increase in the discharge rate $(45-110 \mathrm{~Hz})$. By contrast, oesophageal manipulation in affected animals initiated nerve activity in silent receptors, but the peak discharge rates provoked were lower $(10-55 \mathrm{~Hz})$ than in controls.

\section{CONDUCTION VELOCITIES IN THE VAGUS NERVE} (table 2)

There was no significant difference in the conduc- tion velocities of the mixed nerve action potential in control and affected animals. Although there was no significant difference between the conduction velocities of fibres innervating oesophageal mechanoreceptors in the two groups of animals, it

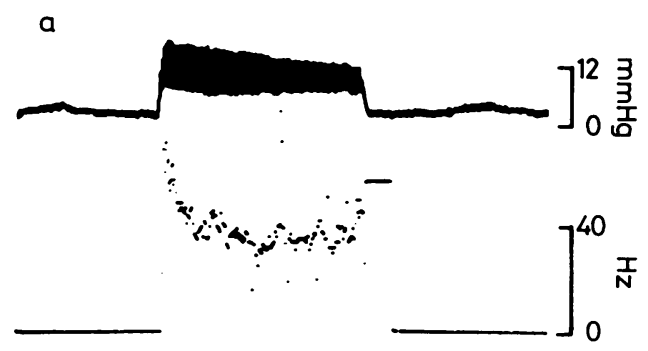

b
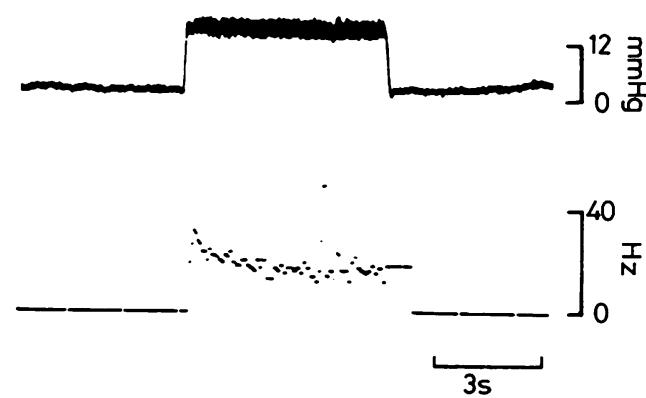

Fig 5 The discharge characteristics of a typical oesophageal mechanoreceptor in a control $(a)$ and acrylamide affected (b) animal during isometric oesophageal contraction. Upper trace, oesophageal pressure; lower trace, impulse frequency. 
Table 2 Conduction velocities in the cervical vagus of control and acrylamide affected animals

\begin{tabular}{|c|c|c|c|c|c|c|}
\hline & \multicolumn{3}{|c|}{ Mixed nerve action potential } & \multicolumn{3}{|c|}{ Oesophageal units } \\
\hline & Number & Range $(\mathrm{m} / \mathrm{s})$ & Mean $(m / s)$ & Number & Range $(\mathrm{m} / \mathrm{s})$ & $\operatorname{Mean}(\mathrm{m} / \mathrm{s})$ \\
\hline $\begin{array}{l}\text { Control } \\
\text { Acrylamide } \\
\text { Significance of difference (Mann-Whitney } \\
\text { test) }\end{array}$ & $\begin{array}{l}5 \\
5\end{array}$ & $\begin{array}{l}60 \cdot 4-79 \cdot 3 \\
62 \cdot 6-77 \cdot 8\end{array}$ & $\begin{array}{l}71 \cdot 8 \\
70 \cdot 9 \\
\text { ns }\end{array}$ & $\begin{array}{l}18 \\
17\end{array}$ & $\begin{array}{r}10 \cdot 7-27 \cdot 7 \\
9 \cdot 7-18 \cdot 3\end{array}$ & $\begin{array}{l}16 \cdot 6 \\
13 \cdot 8 \\
\text { ns }\end{array}$ \\
\hline
\end{tabular}

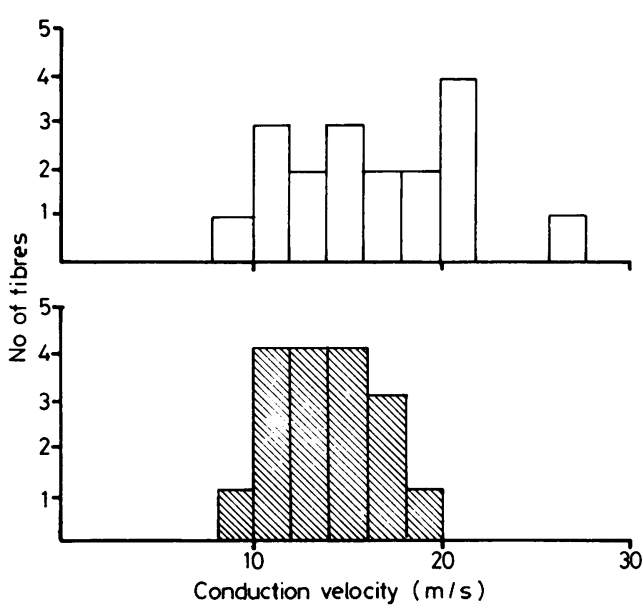

Fig 6 Distribution of conduction velocities of 18 units from control animals (open bars) and 17 units from acrylamide affected animals (stippled bars). Units are in 2 $\mathrm{m} / \mathrm{s}$ bins.

may be seen from fig 6 , in which the spectrum of conduction velocities of fibres innervating units in control and affected animals is compared, that there were fewer fast conduction oesophageal afferents in the affected group.

\section{Discussion}

The present study has demonstrated that there is an increase in the threshold and a decrease in the firing rate of vagal afferent fibres innervating slowly adapting oesophageal stretch receptors in dogs with acrylamide neuropathy. Although the conduction velocities in vagal afferent fibres responding to oesophageal pressure were not lower in acrylamide affected animals than in controls, the distribution of the velocities was consistent with previous observations concerning the relative vulnerability of different nerve fibres in acrylamide neuropathy. ${ }^{12}$ Moreover, "burst" responses that are characteristically found in the fastest conducting oesophageal afferent units of control animals ${ }^{8}$ were not seen in the affected animals. These findings suggest that some of the fastest conducting fibres are nonfunctioning in the acrylamide affected animals and are consistent with previous observations that large diameter, faster conducting fibres are more susceptible to the neurotoxin. ${ }^{2}$ The normal conduction velocity of the fastest conducting fibres contributing to the mixed nerve action potential in the cervical vagus may be explained by the fact that acrylamide causes a distal axonopathy ${ }^{2}$ with the result that afferent fibres, the nerve terminals of which are damaged, may conduct normally in their proximal segments. ${ }^{56}$ Our earlier study, in which conduction of the mixed nerve action potential in the thoracic vagus was mildly impaired, was performed on longer lengths of the vagus as well as on more severely affected animals. ${ }^{4}$

In a previous study on normal greyhounds, it was shown that units with faster conduction velocities had significantly higher firing rates than the slower conducting units. ${ }^{8}$ It was therefore possible that the observation of decreased discharge rate of units in affected animals in the present study was the result of the non-functioning of fast conducting units, rather than of a reduction in the normal discharge rate in individual units. However, a comparison of discharge rates of units with similar conduction velocities $(<18.4 \mathrm{~m} / \mathrm{s})$ demonstrated a significant reduction in discharge rate $(p<0.01)$ in acrylamide affected animals at all but the lowest pressures (fig $5 b)$.

The changes in oesophageal mechanoreceptor function were similar to those reported in hind limb muscle spindles in cats with acrylamide neuropathy, in which firing threshold is raised, dynamic index reduced and firing rate in response to any given degree of muscle stretch is diminished. ${ }^{7}$ In particular, the dynamically responsive, faster conducting, large diameter group Ia afferents are more severely affected by acrylamide than the group II afferents.

The canine oesophageal motility disorder, megaoesophagus, has been attributed to many pathophysiological mechanisms. Observations in dogs with the naturally occurring disorder have included degeneration of the myenteric plexus in some but not all animals, ${ }^{11}$ alterations in the number of neurons in the nucleus ambiguus, ${ }^{12}$ and abnormal neuromuscular function. ${ }^{13}$ Dogs with giant axonal 
neuropathy develop megaoesophagus and have degenerative changes in the vagus nerves and myenteric plexus. ${ }^{14}$ Chronic organophosphorus exposure also results in a canine oesophageal motility disorder. ${ }^{15}$ The function of the afferent innervation of the oesophagus has not been studied in these disorders.

In canine acrylamide neuropathy, it was noted that the oesophagus of animals with established megaoesophagus was able to contract in response to vagal stimulation, and that the motor conduction velocity of oesophageal vagal efferents was normal. ${ }^{4}$ This finding led to the suggestion that dysfunction of oesophageal receptors of afferent fibres might play a key part in the pathophysiology of the disorder. ${ }^{4}$ This suggestion is consistent with the greater susceptibility of sensory than motor fibres to acrylamide. ${ }^{12}$

In this present study, it was not possible to differentiate clearly between dysfunction of the receptor itself and the terminal region of the afferent fibre. However, the former seems to be the more likely site of damage because acrylamide-affected receptors which fire at lower rates in response to oesophageal pressure ramps are nonetheless able to fire at considerably higher frequencies in response to digital pressure during the process of localising the receptor in the oesophagus. Thus it is clear that the terminal region of the afferent fibre is able to conduct at frequencies exceeding those low frequencies occurring during oesophageal pressure ramps. Furthermore, it is well established that the earliest detectable structural and functional changes in acrylamide neuropathy occur in sensory receptors, including Pacinian corpuscles,' and muscle spindles. $^{5-7}$ Muscle spindles have not been identified in the striated muscle of the oesophagus. ${ }^{16}{ }^{17}$

Our study confirms the suggestion that oesophageal mechanoreceptor dysfunction precedes and may underlie the development of megaoesophagus in dogs with gradually evolving acrylamide neuropathy. Normal mechanoreceptor function is likely to be important in the dog because the oesophageal peristalsis is more dependent on the presence of an intraluminal bolus than in other species. $^{18}$ It is possible that in certain naturally occurring disorders of oesophageal motility, damage to the afferent innervation of the oesophagus may well be the primary defect. Similarly, in human dying-back neuropathies, vagal dysfunction, which can be demonstrated by simple screening studies, ${ }^{19}$ may reflect a functional abnormality of the afferent rather than the efferent parasympathetic innervation of the thoracic organs.

The work was supported by a grant from the National Health and Medical Research Council of Australia. The technical assistance of Mrs Virginia
Antidormi is gratefully acknowledged.

\section{References}

' Schaumburg HH, Wisniewski H, Spencer PS. Ultrastructural studies of the dying back process. 1. Peripheral nerve terminal and axon degeneration in systemic acrylamide intoxication. J Neuropath Exp Neurol 1974;33:260-84.

${ }^{2}$ Spencer PS, Schaumburg HH. Classification of neurotoxic disease: a morphological approach. In: Spencer PS, Schaumburg HH, eds. Experimental and Clinical Neurotoxicology. Baltimore: Williams \& Wilkins, 1980:92-9.

${ }^{3}$ Satchell PM, McLeod JG. Megaoesophagus due to acrylamide neuropathy. $J$ Neurol Neurosurg Psychiatry 1981;44:906-11.

${ }^{4}$ Satchell PM, McLeod JG, Harper B, Goodman AH. Abnormalities in the vagus nerve in canine acrylamide neuropathy. J Neurol Neurosurg Psychiatry 1982; 45:609-19.

${ }^{5}$ Sumner AJ, Asbury AK. Physiological studies on the dying-back phenomenon. Muscle stretch afferents in acrylamide neuropathy. Brain 1975;98:91-100.

- Lowndes HE, Baker T, Michelson LP, Vincent-Ablazey M. Attenuated dynamic responses of primary endings of muscle spindles: a basis for depressed tendon responses in acrylamide neuropathy. Ann Neurol 1978;3:433-7.

${ }^{7}$ Lowndes HE, Baker T, Cho E, Jortner BS. Position sensitivity of de-efferented muscle spindles in experimental acrylamide neuropathy. J Pharmac Exp Ther 1978;205:40-48.

${ }^{8}$ Satchell PM. Canine oesophageal mechanoreceptors. J Physiol (Lond) 1983; (in press).

${ }^{9}$ Paintal AS. The conduction velocities of respiratory and cardiovascular afferent fibres in the vagus nerve. $J$ Physiol (Lond) 1953;121:341-59.

${ }^{10}$ Iggo A. The electrophysiological identification of single nerve fibres, with particular reference to the slowestconducting vagal afferent fibres in the cat. $J$ Physiol (Lond) 1958;142:110-26.

" Hoffer RE, Valdes-Dapena A, Baue AE. A comparative study of naturally occurring canine achalasia. Arch Surg 1967;95: 83-8.

${ }^{12}$ Clifford DH, Pirsch JG, Mauldin ML. Comparison of motor nuclei of the vagus nerve in dogs with and without esophageal achalasia. Proc Soc Exp Biol Med 1973; 142:878-82.

${ }^{13}$ Gray GA. Acute experiments on neuroeffector function in canine esophageal achalasis. Am J Vet Res 1974;35:1075-81.

14 Duncan ID, Griffiths IR, Carmichael S, Henderson S. Inherited canine giant axonal neuropathy. Muscle Nerve 1981;4:223-7.

is Harris LD, Ashworth WD, Ingelfinger FJ. Esophageal aperistalsis and achalasia produced in dogs by prolonged cholinesterase inhibition. $J$ Clin Invest 1960;39:1744-51.

${ }^{16}$ Cecio A, Califano G. Neurohistological observations on the oesophageal innervation of the rabbit. Z Zell- 
forsch 1967;83:30-39.

${ }^{17}$ Samarasinghe DD. Some observations on the innervation of the striated muscle in the mouse oesophagus-an electron microscope study. J Anat 1972;112: 173-84.
1* Janssens J. The peristaltic mechanism of the oesophagus. Thesis 1978; University of Leuven, Belgium.

${ }^{19}$ Duncan G, Johnson RH, Lambie DG, Whiteside EA. Evidence of vagal neuropathy in chronic alcoholics. Lancet 1980;ii:1053-6. 